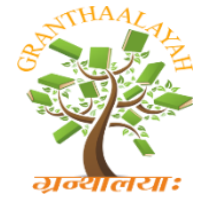

INTERNATIONAL JOURNAL OF RESEARCH GRANTHAALAYAH A knowledge Repository

RAST - 17

\title{
A SHORT REVIEW: REMOVAL OF FLUORIDE IONS FROM GROUND WATER BY USING VARIOUS TECHNIQUES
}

\author{
Prins Satish Jain $^{1}$, S.B. Benaka Prasad ${ }^{2}$, A.V.Raghu ${ }^{3}$ \\ ${ }^{1,2,3}$ Department of Chemistry, Food Technology, Centre for Emerging Technology, School of \\ Engineering Technology, Jain University, India
}

DOI: https://doi.org/10.29121/granthaalayah.v5.i4RAST.2017.3310

\begin{abstract}
Fluoride is an acute toxin, with a rating slightly higher than lead and is present in ground water naturally or artificially. Groundwater in India displays the presence of harmful quantities of fluoride. Fluorspar is main constituent of sand. Under the ground in presence of water when this mineral gets appropriate condition for dissolution, it gets dissolve in water and fluoride ion's get separated from sand. The presence of fluoride causes many health issues to human beings. To reduce these health problems, there is a need to remove fluoride ions from water. This article is brief on different techniques for the removal of fluoride from water.
\end{abstract}

Keywords: Fluoride; Nano Composites; Ground Water; Pretreatment; Adsorption; Isotherm.

Cite This Article: Prins Satish Jain, S.B. Benaka Prasad, and A.V.Raghu. (2017). "A SHORT REVIEW: REMOVAL OF FLUORIDE IONS FROM GROUND WATER BY USING VARIOUS TECHNIQUES." International Journal of Research - Granthaalayah, 5(4) RAST, 98-104. https://doi.org/10.29121/granthaalayah.v5.i4RAST.2017.3310.

\section{Introduction}

Generally, fluoride is present in sellite $\left(\mathrm{MgF}_{2}\right)$, Cryolite $\left(\mathrm{Na}_{3} \mathrm{AlF}_{6}\right)$, fluorspar $\left(\mathrm{CaF}_{2}\right)$. Fluoride occurs naturally in many minerals present inside the ground, like fluorspar, feldspar etc. in presence of water when it gets desirable conditions for solubility it gets dissolved in ground water and separates in form of $\mathrm{F}^{-}$ions and it is very difficult to remove these ions from water. $\mathrm{F}(-)$ ion actually is medicine, as well as a poison. If its concentration is less than $1 \mathrm{mg} / \mathrm{L}$ then it causes dental caries, lack of strength of teeth's, if its concentration is in between $1-1.5 \mathrm{mg} / \mathrm{L}$ it provides enamel on our teeth's. This enamel contains $\mathrm{Ca}_{2}\left(\mathrm{PO}_{4}\right)_{3} \mathrm{~F}$, which is tougher and strong in nature. This enamel provides strength to our teeth's and bones. But if $\mathrm{F}(-)$ concentration exceeds $1.5 \mathrm{mg} / \mathrm{L}$ then more enamel will be formed which is harder, brittle and breaks during collision. Resulting dental health is degraded. And if $\mathrm{F}$ ion is more than $4 \mathrm{mg} / \mathrm{L}$, it acts as a neurotoxin and reduces the growth of mind and reduces the IQ level especially in children. Hence, there is a 
[Jain et. al., Vol.5 (Iss.4: RAST), April, 2017]

ICV (Index Copernicus Value) 2015: 71.21

Recent Advances in Science \& Technology
ISSN- 2350-0530(O), ISSN- 2394-3629(P)

IF: 4.321 (CosmosImpactFactor), 2.532 (I2OR)

InfoBase Index IBI Factor 3.86

need to remove excess fluoride from water and to maintain its concentration in between 1-1.5 $\mathrm{mg} / \mathrm{L}$.

World health organization limit for fluoride concentration is $1.5 \mathrm{mg} / \mathrm{L}$ (WHO, 1985; SMET, 1990), Australian recommended limit is (NHMRC, 2004). Due to increase in industrial activities, the fluoride concentration in main water bodies (rivers, lakes etc.) is also increasing. This water is being used by people unconscious. So there is a huge problem from this fluoride ion concentration. It was found that around $30 \mathrm{mg} / \mathrm{L}$ fluoride ions in some places of world like USA, Africa and Asia. The majority of people affected by fluoride are from tropical region. Because in tropical region, the need of drinking water is more because of heat, $50 \%$ consumption of fluoridated water is increased, because of use of water from wells and bore holes.

It is thus required to bring the concentration of fluoride to required level. The present article reviews the various techniques available for fluoride removal process.

\section{Methods of Removal of Fluoride}

\subsection{Using Brick Powder Adsorbent}

Due to the necessity of techniques which are cost and time efficient researchers searched one of the techniques called adsorption. Though we have techniques like reverse osmosis, nanofiltration, dialysis, and these are efficient, but these are very expensive and time taking. But adsorption technique is efficient, cost is low and time taken is also less. So researchers are going for adsorption techniques.

Dr. Saritha Shara [2016] reported that brick powder can be used for adsorption or removal of fluoride. Her team was in search of easily available, low cost adsorbent and experimented on brick powder which is easily available.

They took brick, powdered it for increasing its surface area, washed with water several times, and activated by heating at $105^{\circ} \mathrm{C}$ for 12 hours. Dried the material then again they crushed it to very fine size and prepared the adsorbent. They studied the adsorption of fluoride on brick powder at different concentration of fluoride, different $p \mathrm{H}$, and also at contact time. They found that at $0.6 \mathrm{gm} / 100 \mathrm{~mL}$ dose of absorbent, at contact time of $120 \mathrm{~min}$, and at $\mathrm{pH}$, removal of fluoride is maximum 56\%. On increasing the $p \mathrm{H}$, amount of adsorbed fluoride decreases. They found that fluoride removal can be increased by increasing adsorbent dose. The adsorbent can be activated by washing with $0.4 \mathrm{~N}$ sodium hydroxide solutions. Eventually they concluded that brick powder adsorbent can be used as nice adsorbent having low cost with efficiency of $56 \%$.

\subsection{Modified Immobilized Activated Alumina}

As alumina is cheap and good adsorbent many efforts were made by the researchers to produce alumina based adsorbent like activated alumina, activated alumina plus manganese dioxide [Maliyekkal et. al. (2006)], hydrous manganese oxide coated alumina [Tenget et. al. (2009)], magnesia amended activated alumina [Maliyekkal 2008]. But all these method have their own disadvantages, it is difficult to remove adsorbent from aqueous solution after the action due to 
[Jain et. al., Vol.5 (Iss.4: RAST), April, 2017]

ICV (Index Copernicus Value) 2015: 71.21

Recent Advances in Science \& Technology
ISSN- 2350-0530(O), ISSN- 2394-3629(P)

IF: 4.321 (CosmosImpactFactor), 2.532 (I2OR)

InfoBase Index IBI Factor 3.86

small size of the particles of adsorbent. Also these are producing $\mathrm{Al}^{+3}$ ions which are toxic and consequently toxicating the water. Consequently Aneeza Rafique (2012) tried to produce an alumina based adsorbent which is immobile, and in the form of granules which can be removed easily from solution after its action and will not release toxic $\mathrm{Al}^{+3}$ ions. They prepared Modified immobilized activated alumina [MIAA] whose efficiency is up to 95\%. They prepared this adsorbent by sol gel method from aluminum tri-sec butoxide, $\mathrm{HNO}_{3}$, ammonia, and paraffin oil. They modified the adsorbent by adding alum to it. They washed the granules obtained thoroughly by distilled water, ethyl alcohol and dried. Later it was calcinated in absence of oxygen at around $450^{\circ} \mathrm{C}$ for $3 \mathrm{~h}$. After this process they obtained MIAA.

They studied the adsorption of fluoride on the given adsorbent for the optimization of conditions like concentration of fluoride, contact time, adsorbent dose, $p H$, effect of stirring rate, temperature etc., They compared the adsorbing capacity of given adsorbent with the capacity of activated charcoal and studied the adsorption phenomenon accordingly. They found MIAA better in all respects than the activated charcoal.

While conducting the experiments they found that adsorption capacity increases with increase in adsorbent dose up to a maximum dose. This maximum dose is optimum dose. They found maximum dose for adsorption as $10 \mathrm{~g} / \mathrm{L}$. They also found that adsorption capacity increases as contact time increases. They found that $60 \mathrm{~min}$. is the maximum contact time up to which maximum defluoridation occurs and equilibrium is achieved. Adsorption found to increase with increase in stirring rate as contact area increases. Adsorption studies also showed that MIAA has good adsorbing properties.

They showed that adsorbent can be regenerated thermally and chemically. In thermal regeneration, adsorbent was heated at $450^{\circ} \mathrm{C}$ for $30 \mathrm{~min}$. In chemical regeneration adsorbent soaked in $0.1 \mathrm{~N}$ sodium hydroxide for $2 \mathrm{~h}$, and then washed with distilled water until $p \mathrm{H}$ becomes neutral. After several experiments they found that thermally regenerated MIAA is good adsorbent and can be used up to 5 regeneration cycles. Its working degrades negligibly in each regeneration cycle. But for chemically regenerated MIAA working is degraded in more amounts for each cycle. After doing all the experiments they found that the thermally regenerated MIAA is best adsorbent with efficiency up to $95 \%$. They also found that the capacity of MIAA is 0.76 $\mathrm{mg} / \mathrm{g}$ for the fluorides.

\section{Biosorbents [Rice Husk, Wheet Husk, Neem Leaves, Pimple Leaves, Neem and Pimple Leaves Mix]}

Using inorganic adsorbents were used extensively to remove the fluoride, it become more expansive and display many side effects. Resulting, development of novel bio-sorbents materials, which are naturally available and having a low cost. Sharad Sharma 2014, reported that finely grinded dry neem leaves, grinded pimple leaves, powdered dry ground-nut shells, rice husk and wheat husk can also be used as bio-sorbents for adsorption of fluoride.

They studied the adsorption of fluoride for various doses of adsorbent, initial concentration of fluoride in water, contact time, $p \mathrm{H}$ and found that for optimum dosage of $6 \mathrm{~g} / \mathrm{L}$ the adsorption is max. They also discovered that change in $p \mathrm{H}$ doesn't have any impact on defluoridation. From 
their experiments they eventually concluded that the listed bio-sorbents can act as better, low cost adsorbent for defluoridation. The efficiency of given bio-sorbents is listed below Table 1 .

Table1. Efficiency of bio-sorbents using natural leaves

\begin{tabular}{|l|l|}
\hline Material & Efficiency (\%) \\
\hline Pimple leave & 90.2 \\
\hline Neem bark & 94.5 \\
\hline Wheat husk & 94.5 \\
\hline Neem pimple mix & 94.6 \\
\hline Ground nut shell & 98.0 \\
\hline Rice husk & 98.2 \\
\hline
\end{tabular}

Eventually they concluded that among the listed bio-sorbents rice husk and powdered groundnut shell adsorbents can act as best, low cost, efficient bio-sorbents for adsorption of fluoride with the efficiency of $98.2 \%$ and $98 \%$ respectively.

\section{Fly Ash After Pretrearment}

Ranjeeta S. et. al. 2015 reported that from home chullas can be used as an adsorbent after its pretreatment. As fly ash has bad effects on water it is pre-treated to eliminate this bad effect before the use. They reported about the defluoridating action of fly ash. The reason for that is fly ash contain a unburnt carbon, oxides of calcium and iron in it which produces irregular surface and active sites required for the adsorption to happen. Also due to the fine particles surface area required for adsorption becomes more.

They conducted experiments for the optimization of conditions like adsorbent dose, contact time, $p \mathrm{H}$, rate of agitation, initial fluoride concentration etc., after experiments they found that at the optimum dosage of $100 \mathrm{~g} / \mathrm{L}$ and for contact time of $2 \mathrm{~h}$ maximum defluoridation occurred on the pre-treated fly ash adsorbent. Finally they concluded that pre-treated fly ash has good adsorbing properties and can be used as effective adsorbent as it is costless and easily available.

\section{Carbonised Pomegranate Seeds [Cpgc=Carbonise Pomeca Granatum Carbon]}

Sudhansh Kanaujia (2015) showed that carbonized pomegranate seeds can be used as adsorbent for defluoridation. Using pomegranate seeds, dried them, carbonized them and grinded the product to fine sizes. Different sized batch of adsorbent they took and analyzed the adsorption phenomenon for the optimization of conditions like adsorbent dose, contact time, $p \mathrm{H}$, initial concentration of fluoride and particle size. After conducting several experiments they made a conclusion like batch of adsorbent having particle size $55 \mu \mathrm{m}$, at the optimum dosage of $0.75 \mathrm{~g}$, at $p \mathrm{H} 5.5$ and at contact time of 75 min can act as good adsorbent. They also studied adsorption for different solution having initial fluoride concentration 2, 4, 6, 8, and $10 \mathrm{mg} / \mathrm{L}$. And found that when concentration of fluoride is $2 \mathrm{mg} / \mathrm{L}$ efficiency of adsorbent is $88 \%$, but as the concentration of fluoride increased up to $10 \mathrm{mg} / \mathrm{L}$ efficiency is reduced to $47 \%$. While studying the effect of other anions they got to know that bicarbonates have adverse effect on fluoride adsorption. As the concentration of bicarbonates increases in solution defluoridation decreases. They also 
studied the Freundluich and Langmuir isotherms and found that data fit well in Langmuir isotherm. Eventually they concluded that CPGC has good adsorbing property.

\section{Ramcham [Vetiver Root] Adsorbent or Bio-Sorbent}

Due to advancement in adsorption techniques, researchers went for the newer adsorbent and more for the naturally available bio-sorbents. Researchers got to know that medicinal plants, plant roots, seeds can be used to make adsorbents. Puthenveedu Sadasivan Pillai Harikumar (2011) reported that vetiver root, activated can be used as bio-sorbent for fluoride removal. First they activated vetiver root by heating and then grinding very fine. After that they studied the structure of activated vetiver root adsorbent and revealed that its structure has high porosity and large surface area and can be used as adsorbent. Later they started adsorption studies and investigated for the like adsorbent dose, contact time, agitation time, $p \mathrm{H}$ and initial fluoride concentration. They found that optimum dose of $0.5 \mathrm{~g}$ of adsorbent, particle size of 100 micron, and at neutral $p \mathrm{H}$, activated powdered vetiver root adsorbent can act as good bio-sorbent having efficiency up to $90 \%$. They found that with increase in agitation time, adsorption increases and later become constant. Finally they studied the Langmuir and Frendluich isotherms, and data found to be in good agreement with Langmuir isotherm and Frendluich isotherm both. Resulting they concluded that activated powdered vetiver root can be used as good adsorbent with efficiency $90 \%$. In similar fashion they studied adsorption capacity of adsorbent prepared from tamarind seeds and found that it is $75 \%$ efficient.

\section{Nano Composites}

Nano carbon fibers obtained from bermuda grass (cynodon dactylon) coated with iron oxide Nano particles like titanium oxide nano particles act as nano composite. It was known to researcher about adsorbing property of nano composites for the fluoride. Robert V.D. 2015, reported that micro carbon fibers prepared from pulverized dry Bermuda grass \{cynodondactylon\} can be used as an adsorbent. His team, next he reported that nanocarbon fibers prepared from micro carbon fibers when coated with iron oxide nanoparticles and titanium oxide nanoparticles enhances its adsorbing action. Adsorption study for all three adsorbent 1) Micro carbon fiber 2) Iron oxide coated carbon nano fiber 3) Titanium oxide coated carbon nano fiber was done separately. They first prepared iron based carbon nano fibers [IBCNF] and titanium based carbon nano fiber [TBCNF] by the technique of chemical vapor deposition (CVD). Then they studied the adsorption for optimization of conditions like $\mathrm{PH}$, contact time, adsorbent dose, and initial fluoride concentration. They found that all three adsorbents can act as good adsorbing agents at optimum dosage of $0.5 \mathrm{~g}$, contact time of $60 \mathrm{~min}$, and at $\mathrm{pH}$. They also analyzed isotherms for the data obtained and found that data fits well in in Frendluich isotherm.

Adsorbing action of micro carbon fibers attributed to fact that its surface contains channels and cavities. The adsorbing action of nano carbon fibers was due to coating of nanoparticles of iron oxide and titanium oxide. They also found that as $\mathrm{PH}$ increases adsorbing action decreases. Eventually they found that the fluoride removal efficiency for micro carbon fibers, iron based carbon nano fibers [IBCNF] and titanium based carbon nanofibers [TBCNF] is as shown in the following Table 2. 
Table 2: The fluoride removal efficiency.

\begin{tabular}{|l|l|}
\hline Material & Efficiency (\%) \\
\hline Micro-carbon Fibers & 84 \\
\hline Iron based Carbon nano fibers & 96 \\
\hline $\begin{array}{l}\text { Titanium based carbon nano } \\
\text { fibers }\end{array}$ & 92 \\
\hline
\end{tabular}

Finally they concluded that iron based carbon nano fibers adsorbent is superior adsorbent for fluoride.

\section{Eggshell Powder [Bio-Sorbent]}

An egg shell is made of calcium carbonate (94.03\%) and also contains calcite. It has cellulosic structure and contains amino acids. Hence it was expected to have good adsorbing properties. R. Bhumika [2011] reported about the adsorbing action of egg shell powder. They prepared egg shell powder by washing, drying and seizing to very fine size $(100-350 \mu \mathrm{m})$. They studied the surface morphology of egg shell powder by SEM and found that, its surface is highly irregular and have heterogeneous pores and cavities, and large surface area. It gave them idea that egg shell powder can be used as adsorbent for fluoride. They studied the adsorption of fluoride on egg shell powder for optimization of conditions like adsorbent dose, $p H$, contact time, particle size and initial fluoride concentration. The study revealed that adsorption of fluoride increases with increase in $p \mathrm{H}$ up to 6 . After 6 as $p \mathrm{H}$ increases defluoridation decreases. This study also displays that as adsorbent dose increases adsorption increases. After optimum dosage adsorption becomes constant. Then they studied the variation of adsorption with temperature and found that defluoridation is favorable at low temperature. Isotherm studies showed that data fits in Langmuir isotherm exactly and fairly with Frendluich isotherm. As initial concentration of fluoride ion increases resulting adsorption decreases. Finally they concluded that at optimum dosage of $2.14 \mathrm{~g}, p \mathrm{H} 6$, contact time of $120 \mathrm{~min}$, agitation speed $250 \mathrm{rpm}$ and at temp $323 \mathrm{~K} \mathrm{egg}$ shell powder can act as good adsorbent for defluoridation with capacity of $(1.09 \mathrm{mg} / \mathrm{g})$ for monolayer adsorption. It is good, natural, low cost adsorbent with efficiency of $90 \%$.

\section{References}

[1] K. A. Ennanuel, G. Ramaraju, A. Rambabu, and V. Rao, (2008) "Removal of fluoride from drinking water with activated carbon prepared from HNO3 activation-a comparative study," Rasayan Journal of Chemistry, 4, 802-818..

[2] Y.Sun, Q. Fang, J. Doung, X.cheng, and J. Xu, (2011) "Removal of fluoride from drinking water by Natural Stilbite zeolite modified with Fe(-)," Desalination, 277, 1-3, 121-127.

[3] S. P. Kamble, S. Jatap, N. K. Labhsetwar, (2017) "Defluoridation of drinking water using chitin, chitosan and lanthanum modified chitosan," Chemical Engineering Journal, 129, 1-3, 173-180.

[4] E. Kumar, A. Bhatnagar, U.Kumar and M. Sillanpaa, (2011) "Defluoridation from aqueous solutions by nano-alumina: characterization and sorption studies," Chemical Engineering Journal of Hazardous Materials, 186, 2-3, 1042-1049.

[5] A. R. Tembhurkar, and S. Dongre, (2006) Journal of Environmental science and Engineering, 48, 3, 151-156.

[6] S. M. Maliyekkal, A. K. Sharma, and L. Philip, (2006) "Manganese-oxide-coated alumina: a promising sorbent for defluoridation of water," Water Research, 40, 19, 3497-3506. 
[7] S. S. Tripathy, J. L. Bersillon, and K. Gopal, (2006) "Removal of Fluoride from drinking water by adsorption onto alum-impregnated activated alumina," Separation and Purification Technology, 50, 3, 310-317.

[8] Kavita Panchore, Dr. Sarita Sharma, Dr. Ashoke Sharma and Dr. Sanjay Verma (2016)

[9] L.M. Camacho, A. Torres, D. Saha, S. Deng, (2010) Adsorption equilibrium and kinetics of fluoride on sol-gel-derived activated alumina adsorbents, J Colloid Interface Sci. 349, 307-13.

[10] G. Buelna and Y. S. Lin, (1999) "Sol-Gel Derived Nano-porous g-Alumina Granules", Mesoporous and Microporous Materials, 30, 359-369 (1999)

[11] S. Deng, V. Viswanathan, and D. Candelaria, (2006) "Sol-Gel Derived Mesoporous Alumina for Fluoride and Arsenic Removal from Drinking Water" New Mexico J. of Sci., 44, 183-202.

[12] G. Alagumuthu, V. Veeraputhiran and R. Venkataraman, (2011) "Fluoride Sorption Using Cynodon dactylon-Based Acti- vated Carbon," Hemijska Industrija, 65, 1, 23-35.

[13] Aneeza Rafique, M. Ali Awan, Ayesha Wasti, Ishtiaq A. Quazi , and Muhammad Arshad (2012), Removal of Fluoride from Drinking Water Using Modified Immobilized Activated Alumina, Journal of Chemistry, Article ID 386476, 7 pages.

[14] Sharad Sharma ,Vibhuti and Aditya Pundhir (2014) Removal of Fluoride from Water Using Bioadsorbents, Current Research in Microbiology and Biotechnology, 2, 6, 509-512.

[15] Ranjeeta S. (2015), Removal of Fluoride from Drinking Water Using Fly Ash after Pre Treatment. J Environ Anal Toxicol S7: 004.

[16] Sudhanshu Kanaujia , Bharat Singh, Sanjay Kumar Singh. (2015) Comparative Study on Removal of Fluoride from Groundwater by Natural and Modified Bagasse Carbon of Sugarcane, International Research Journal of Pure and Applied Chemistry, ISSN: 2231-3443, 8, 3.

[17] PuthenveeduSadasivan Pillai Harikumar, ChonattuJaseela, TharayilMegha. (2011) Defluoridation of water using biosorbents, Natural Science, 4, 4, Article ID: 18628, 7 pages.

[18] Tapan K Rout, ReetaVerma, Robert V. Dennis, Sarabjit Banejee. (2015) Study the removal of fluoride from aqueous medium by using nano-composites, Journal of Encapsulation and Adsorption Sciences 5, 1, 38 .

[19] R. Bhumika, N. K. Mondal, B. Das, P. Roy, K. CC. Pal, C. Das, A. Banerjee, and J. K. Datta. (2011) Eggshell Powder as an Adsorbent for Removal of Fluoride from Aqueous Solution: Equilibrium, Kinetic and Thermodynamic Studies, E-Journal of Chemistry, 9(3), 1457-1480.

*Corresponding author.

E-mail address: gsraghu2003@yahoo.co.in/benakaprasad@gmail.com 